\title{
Recognizing the benefits of above-ground carbon sequestration in the carbon footprint of products derived from woody perennial systems
}

Plassmann, Katharina; Norton, Andrew

\section{Carbon Management}

DOI:

10.1080/17583004.2017.1362947

Published: 01/08/2017

Peer reviewed version

Cyswllt i'r cyhoeddiad / Link to publication

Dyfyniad o'r fersiwn a gyhoeddwyd / Citation for published version (APA):

Plassmann, K., \& Norton, A. (2017). Recognizing the benefits of above-ground carbon sequestration in the carbon footprint of products derived from woody perennial systems. Carbon Management, 8(4), 343-349. https://doi.org/10.1080/17583004.2017.1362947

\footnotetext{
Hawliau Cyffredinol / General rights

Copyright and moral rights for the publications made accessible in the public portal are retained by the authors and/or other copyright owners and it is a condition of accessing publications that users recognise and abide by the legal requirements associated with these rights.

- Users may download and print one copy of any publication from the public portal for the purpose of private study or research.

- You may not further distribute the material or use it for any profit-making activity or commercial gain

- You may freely distribute the URL identifying the publication in the public portal ?
}

Take down policy

If you believe that this document breaches copyright please contact us providing details, and we will remove access to the work immediately and investigate your claim. 
The Version of Record of this manuscript has been published and is available in Carbon Management 8, 343-349, 23. August 2017, http://tandfonline.com, http://dx.doi.org/10.1080/17583004.2017.1362947

Recognizing the benefits of above-ground carbon sequestration in the product carbon footprint of perennial crops

Katharina Plassmann ${ }^{\mathrm{a} *}$ and Andrew Norton ${ }^{\mathrm{b}, \mathrm{c}}$

${ }^{a}$ Yara International ASA, Research Centre Hanninghof, Hanninghof 35, 48249

Dülmen, Germany

${ }^{b}$ Renuables, 41 High Street, Menai Bridge, Isle of Anglesey, LL59 5EF, UK

${ }^{c}$ School of Environment, Natural Resources and Geography, Bangor University,

Deiniol Road, Bangor, Gwynedd, LL57 2UW, UK. E-mail: a.norton@bangor.ac.uk; telephone 0044-7900-560402

*Corresponding author. E-mail: katharina.plassmann@yara.com; telephone: 00492494-798109 


\title{
Recognizing the benefits of above-ground carbon sequestration in the carbon footprint of products derived from woody perennial systems
}

\begin{abstract}
Calls are increasingly made for the inclusion of carbon sequestration in the product carbon footprint (PCF) of the outputs of managed woody perennial systems. However, due to a lack of common methods and methodological difficulties, the current application is inconsistent and often fails to address important issues, limiting the usefulness of available estimates of the climate mitigation potential of such systems.
\end{abstract}

Suggestions are made for the future application of methods, and three situations are identified here in which it is meaningful to give credits for biogenic carbon: if management or land use changes increase total carbon stocks; if biogenic carbon replaces fossil fuels; and if biogenic carbon is stored for more than 100 years. Where these conditions are not met, other mechanisms should be used to incentivize increasing carbon stocks. All co-products arising from a plantation across its entire life cycle should be included in PCF calculations, based on a holistic view of the plantation.

The aim is to reduce the inconsistency in current PCF calculations for products from woody plantations and to ensure that their climate mitigation potential is recognized in a meaningful way under the framework of product related carbon accounting, thereby incentivizing climate friendly management methods.

Keywords: greenhouse gas emissions; tree crops; biogenic carbon; carbon stocks; carbon removals 


\section{Introduction}

Product carbon footprints (PCFs) estimate the amount of greenhouse gases (GHGs) emitted during the life cycle of goods or services, either including entire supply chains or parts thereof. GHG emissions from crop production arise mainly from the manufacture and transport of farming inputs, energy use, farming operations and microbial activity in cultivated soils. Another significant source of emissions can be the loss of carbon stored within forests and other ecosystems upon their conversion to agriculture.

GHG emissions related to land use change (LUC) are commonly included in PCF methodologies in an attempt to incentivize a reduction in LUC. For example, the major international PCF guidelines PAS 2050 (BSI, 2011) and the GHG Protocol Product Life Cycle Accounting and Reporting Standard (GHG Protocol Product Standard) (WRI and WBCSD 2011) account for carbon stock changes in soils and biomass due to recent LUC up to 20 years or a single harvest period prior to the assessment, whichever is longer. In Life Cycle Assessments (LCAs), LUC emissions have not routinely been included in the past but are increasingly included now (Cederberg et al., 2011). Changes in soil carbon are either excluded (PAS 2050) or not mandatory (GHG Protocol Product Standard) if no recent LUC has occurred.

The carbon contained in biogenic materials that are part of the product analyzed may be excluded under PAS 2050 for food and feed products due to the likely reemission of the stored carbon to the atmosphere at short time scales. The GHG Protocol Product Standard and ISO (2013) allow the inclusion of biogenic carbon for all products and require the separate reporting of the timing of the removal and the emission for reasons of transparency. Carbon sequestration and carbon stocks in biomass that do not become part of the product analyzed (e.g. wood of fruit trees) are not included in PAS 2050 and the GHG Protocol Product Standard. For perennial 
agricultural systems that may store large amounts of carbon this means that their climate mitigation potential is not fully recognized in PCFs.

Overall, there is currently no general consensus on how to include temporary carbon removals in product level carbon accounting (Cederberg et al., 2011; Jørgensen and Hauschild, 2013). Nevertheless, calls are increasingly made for the inclusion of carbon sequestration in PCFs in order to better represent woody perennial systems (e.g. Noponen et al., 2013), and in these early days of developing the methods, some recent studies and online carbon calculators make an attempt to include carbon sequestration (Lam et al., 2009; Petsri et al., 2013; Andrade et al., 2014; Maina et al., 2014). However, due to a lack of common methods and methodological difficulties, the current application is inconsistent and often fails to address important issues that are discussed here. This limits the usefulness and scientific credibility of available estimates and potentially overestimates the positive climate impact of perennial plantations (Nair and Nair, 2014). Further, there appears to be some uncertainty about the potential to achieve carbon neutrality by balancing GHG emission against on-farm carbon sinks, e.g. in the coffee industry (Haggar and Schepp, 2012).

Therefore, it is timely to discuss the issue of carbon sequestration in managed woody plantations. Managed woody perennial systems here include: tree crops, plantations that produce non-timber products as their main output (e.g. latex), and systems that combine crops with trees or shrubs (agroforestry). Grasslands and systems with non-woody perennial crops are not the focus of this study. The main aim of PCFs is to provide information to an audience that in turn can reduce GHG emissions related to products, thus incentivizing climate friendly management methods. This article is concerned with how to improve the practical inclusion of above-ground carbon removals in the PCF of both woody (e.g. timber) and non-woody products (e.g. coffee) derived from the systems described above. It highlights some methodological issues that 
need to be resolved in order to estimate the climate mitigation potential of managed systems that contain trees and shrubs in a meaningful way under the framework of product related carbon accounting, distinguishing between biomass that is part of the product and biomass within the wider perennial system. Further, it aims to reduce the current inconsistency in the calculation of PCFs and proposes ways that allow individual farmers to benefit from maintaining or increasing carbon stocks. The latter is particularly relevant for developing countries where important crops are grown in perennial systems but farmers' efforts to increase carbon stocks currently are not recognized in PCFs.

\section{Methodological issues}

Several methodological issues complicate the inclusion of carbon removals in PCFs from woody perennial systems: the difference between stocks and sequestration; the non-permanence of the removals; the focus only on the carbon that is contained in the product being analyzed; allocating removals between co-products from the same system; and the common failure to consider the entire system over its full life time. Further issues not discussed here include potential accounting errors where removals outweigh emissions (Plassmann 2012) and the lack of good quality data for many systems (Nair et al., 2009). These issues are equally relevant in the context of soil carbon sequestration.

\section{Carbon stocks vs. sequestration}

In the context of mitigation benefits of perennial biomass carbon, it is important to distinguish between carbon stocks and carbon sequestration as two separate indicators. The purpose of PCFs is quantifying fluxes (in units of $\mathrm{C}$ per year) and relating them to yields at defined time scales, not quantifying carbon stocks (in units of C). Carbon 
stocks cannot be included in PCFs, only fluxes.

In a rotational woody perennial system that is renewed at the end of each crop cycle, carbon stocks and sequestration rates differ greatly between the establishment phase and the mature phase of each cycle. Over several rotations, the long term carbon stocks can be expressed as the average carbon contained in the biomass at any one time, where this time averaged carbon stock is constant across rotations. There is no net sequestration over long time scales (unless LUC or management changes occur) and PCFs should therefore not include it. This is an important difference between PCFs and project or national carbon accounting where absolute carbon stocks may be considered without relating them to a particular (annual) yield.

\section{Non-permanence of carbon sequestration}

At constant levels of productivity, any GHG not emitted contributes to mitigation and a reduced PCF because any emission that is avoided in the first place cannot be re-emitted (Smith et al., 2014). In contrast, including carbon sequestration in PCFs is more complicated due to the likely non-permanence of the sequestration. The carbon contained in food, feed and crop residues is on a short cycle, i.e. it is released back into the atmosphere at time scales too short to contribute effectively to climate mitigation. Only long lasting carbon sinks can do this, and this is why the inclusion of carbon sequestration in biomass needs to consider the timescale of the emission of the stored carbon.

If biomass carbon sinks were included irrespective of whether this biomass is used as a valuable resource (e.g. building materials) or disposed of as a waste, then the aim of PCFs to give incentives for mitigation efforts would not necessarily be achieved. If, for example, the trees in a perennial plantation are clear felled and burned at the end of the economic cycle then there is no net carbon sequestration and no carbon benefit 
should be given to the products derived from this plantation. The usefulness and quality of available studies is seriously affected by the short timescale of most studies in agroforestry systems and a lack of consideration of the timescale of the re-emission (Nair and Nair, 2014).

Some authors argue that only truly long-term carbon storage over at least 1000 years offers real climate benefits (Jørgensen and Hauschild, 2013), whereas others stress that short-term storage can provide immediate benefits that buy society more time to develop longer lasting solutions (e.g. Dornburg and Marland, 2008). The LCA community concluded that biogenic carbon should not be included in LCAs (Vogtländer et al., 2014).

However, based on the increasing desire of stakeholders to include biogenic carbon in LCAs and PCFs, BSI (2011), WRI and WBCSD (2011) and EC-JRC (2010) allow giving credits for emissions that are delayed beyond the commonly used 100-year assessment period. Products with a lifetime greater than 100 years can claim a benefit for stored carbon unless otherwise provided for in supplementary sector/product specific requirements. Any carbon stored beyond this period is considered as permanently stored.

\section{Failure to consider the entire system}

In perennial systems there are significant carbon fluxes that are an integral part of the system but do not become part of the product, and these are typically excluded from PCFs, e.g. the carbon contained in an apple but not the apple tree (BSI, 2011; WRI and WBCSD, 2011). It is possible to include the latter under PAS 2050 but its exclusion is recommended (BSI, 2011). Published LCA studies either include biogenic carbon in a fruit but not the fruit tree (e.g. Coltro et al., 2009) or exclude it entirely (e.g. Mourad et al., 2007). 
Moreover, several co-products may be derived from woody perennial systems. LCA and PCF guidelines prescribe the allocation of GHG emissions between coproducts from common processes, e.g. rubberwood and latex, and this should also apply to carbon removals and avoided emissions. However, current practice appears to commonly fail to account for all co-products from perennial plantations. One possible reason for this omission is that most perennial crop LCAs do not consider the full lifetime of the plantation (Bessou et al., 2013); however, some co-products will arise only at the very end of its economic life, e.g. rubberwood. The results of an analysis will therefore depend on whether or not all co-products are analyzed, leading to inconsistencies and a lack of comparability between studies. Another possible reason is that perennial systems may be very diverse and provide various functions, making the allocation of GHG emissions and removals between co-products a complex task.

Further, in the early years of a plantation, carbon sequestration is rapid and stocks are low; in mature plantations, the situation is reversed. Including yearly snapshots of sequestration in PCFs is not meaningful because it does not reflect this reality of rotational systems. It can generate misleading conclusions because the result will be highly dependent on the age of a plantation. Users of online carbon calculators that include sequestration need to be aware of this restriction when interpreting results.

\section{Towards increased consistency}

Three situations are identified in which it is meaningful to give credits for biogenic carbon: if management or LUC increase total carbon stocks; if biogenic carbon replaces fossil fuels; and if biogenic carbon is stored for long timescales. The following suggestions are intended to increase consistency in PCF applications. 


\section{Include both LUC and management induced changes}

Long-term carbon stocks can be increased via LUC (e.g. from degraded land to tree crops) or management changes (e.g. increasing the amount of shade trees). The impact of LUC is captured by current PCF methods whereas the impact of changed management practices is not included. Similarly, carbon stock decreases via LUC are currently included but decreases resulting from management changes are not.

Changes in standing stocks via management changes should be treated in the same way as LUC, i.e. by comparing time averaged stocks before and after the change and allocating the increase/decrease evenly across 20 years or a single harvest period, whichever is longer.

This approach could incentivize management changes that lead to the sequestration of carbon. As Vogtländer et al. (2014) explain, this sequestration on individual farms does not necessarily lead to increased total global sequestration which can only be achieved by a growth in the global forest area and a global growth in the application of wood in the building sector. However, the approach suggested here is believed to be useful to incentivize individual stakeholders to increase carbon sequestration by changing processes that are under their own control by recognizing their efforts in PCFs.

\section{Give credits for replacing fossil fuels}

System expansion and substitution should typically be avoided in attributional PCFs. However, in the case of bioenergy a credit could be given to a perennial system with constant time-averaged carbon stocks if its biomass is used to replace fossil fuels as long as the time-averaged stocks do not decrease. This approach is accepted in LCAs (EC-JRC, 2010) and PAS 2050. The GHG Protocol Product Standard does not allow avoided emissions to be subtracted from the total inventory results but they may be 
reported separately. Giving credits should be limited to those cases where the substituted product can be unambiguously identified. If it is unlikely that fossil energy will be replaced the system should not receive any credits if it is in a long-term equilibrium without any net sequestration.

\section{Temporary storage: apply established methods while building consensus}

The typical lifetime of a plantation is considered too short to include carbon sequestration as a credit. While common methods apply the 100-year cut-off rule for durable products (BSI, 2011; WRI and WBCSD, 2011), both the inclusion and the appropriate time horizon are debated (Jørgensen and Hauschild, 2013; Vogtländer et al., 2014) so there is a need within the relevant communities to agree on the most suitable timescales for giving credits to biogenic carbon storage. Credits given for a storage length of >100 years do not imply a saving of carbon emissions but often only a delay, and it is important to explicitly consider both short-term and long-term mitigation effects (Jørgensen and Hauschild, 2013). Further discussions are needed to enable useful calculations that can contribute to climate mitigation, find the most appropriate balance between short-term mitigation and long-term storage, define the most appropriate time horizons that can achieve the aims of PCFs, and decide how to address both scientific and pragmatic considerations. In the meantime, it is suggested to follow the established rules in BSI (2011) and WRI and WBCSD (2011).

\section{Take a holistic view of perennial systems and align methods for co-product allocation}

A holistic systems view is advocated which includes all products, components and coproducts of perennial systems across entire rotations. The narrow analysis of only a short time span is a major limitation of many existing studies because basing the 
calculations on one or a few years only allows neither an adequate holistic assessment of environmental impacts nor comparisons between systems, sites or years. This is because it fails to represent the reality of perennial systems which includes unproductive years, variations between yields and inputs over the productive phase, and declining yield levels towards the end of the economic life (Bessou et al., 2013). Where the aim of a PCF analysis is the external communication, comparison between sites, suppliers or regions, or tracking mitigation benefits over time, this approach is not suitable. Considering all products from a common system is also important for incentivizing the most efficient use of land.

In this context, the issue of co-product allocation is of great importance. LCA and PCF guidelines require that all co-products are considered that arise from systems where it is not possible to divide the unit processes so that only the inputs and outputs to one of the co-products are included. The products can be derived from the same plant, e.g. latex and rubberwood, or from different plants that are both part of the system, e.g. coffee beans and timber from shade trees.

The two most common methods of allocation are physical and economic allocation. Physical allocation is based on an underlying physical relationship between the co-products and GHG fluxes, where the quantity of both co-products and emissions are correlated. Economic allocation splits the GHG emissions according to the economic value of the co-products. This is the preferred allocation method if no physical relationship can be established or does not adequately describe the GHG fluxes (WRI and WBCSD 2011).

If the carbon in the rubberwood was physically traced then all carbon removals would be credited to the wood product. This can be questioned because latex is the main economic driver for maintaining rubber plantations and both products are derived from the same tree, suggesting economic allocation. In the case of shaded coffee plantations, 
the two products timber and coffee are not derived from the same plant, but shade tree timber could be regarded as a co-product just like rubberwood, arguing that the shade trees would not exist if it was not for the main product coffee. Moreover, allocation based on physical relationships should only be used if all co-products have a function or value that is related to the physical measure chosen (RSB 2011; WRI and WBCSD 2011). For the different products from perennial plantations such as woody biomass, food or feed it will rarely be possible to find such a common function.

On the other hand, a durable wooden product or building materials that store carbon for long periods of time should be recognized for their climate mitigation benefits. It would be easier to base this benefit on the amount of carbon contained in the final product than having to account for possible losses along the value chain from plantation to final product because the initial benefit at the plantation gate is split between co-products. This would mean not to allocate any benefits to the non-wooden outputs of a plantation.

In conclusion, there are arguments for both economic allocation and a physical tracing of the sequestered carbon, and there is a need for alignment of methods so that the overall mitigation potential of the system can be maximized. In any case, the actual carbon that is contained in a long-lived (co-) product that is used e.g. as a building material should be declared as a second indicator that can help incentivize the use of such renewable products over conventional alternatives.

\section{Incentivize the use of long lived bio-derived products}

The use of long-lived natural fibre products such as building materials should be incentivized for climate mitigation and consumers made aware of their positive impact relative to alternative materials. Categories of products with expected lifetimes over 100 years should be defined, and methods are needed to estimate and declare the climate 
benefit of such materials, whether they are the sole output or a co-product of a woody system. A pragmatic option would be the development of default figures for different materials to declare a product's carbon contents if more accurate data is not available.

The producers of crops in perennial plantations and the communities that use long-lived biomaterials should align their methods regarding carbon sequestration for carbon footprinting calculations and consumer facing carbon labels. Their interests may differ somewhat: perennial tree crop producers have a desire to be able to allocate at least some of the carbon sequestration benefits to their products, even if none of the sequestered above-ground carbon ends up in the crop as such but in a co-product of the wider system. On the other hand, renewable building materials should be recognized for their climate mitigation benefit if they are long-lived, in particular in comparison with conventional non-renewable building materials. These diverging interests need to be discussed and aligned as much as possible.

\section{Use other methods to incentivize above-ground carbon stocks where they cannot be included in PCFs}

PCFs are the wrong instrument for incentivizing efforts for maintaining carbon stocks in situations other than outlined above because they only consider fluxes, not stocks. Stock changes via LUC are recognized but their impact - positive or negative - is spread evenly across 20 years or a single harvest period. After this time, it is assumed that a new equilibrium has been reached.

This does not mean that the contribution of perennial systems to climate mitigation should not be considered at all in such cases. Other mechanisms should then be used to incentivize maintaining carbon stocks which are also important for adaptation, resilience, biodiversity and ecosystem services (Tscharntke et al., 2011). 
Therefore, it is proposed that carbon stocks should be evaluated separately from GHG fluxes and considered as a second indicator alongside a system's PCF. This is similar to the requirement of ISO/TS 14067 to show carbon storage within the product analyzed separately from GHG emissions, but applies to the wider perennial system (e.g. including trees that are part of the plantation but do not become part of the product analyzed). All else being equal (i.e. the same management practices, yield levels and delivery of other ecosystem services), a system with higher carbon stocks per hectare should be preferred over one with lower carbon stocks. It is important however to consider the age structure of the sites to be compared in order to avoid misleading comparisons and conclusions. Ideally, time averaged carbon stocks would be used. This use of an average also incentivizes consistent good farming practice by not reporting fluctuating stocks depending on the stage of rotation.

Carbon accounting per hectare only (instead of per unit of product) is not recommended because it does not take into account the productivity of the system. The combination of per hectare accounting for stocks and product related PCF assessments will be able to address both issues. The environmental benefits provided by woody perennial systems can also be recognized via sustainability certification schemes, payments for ecosystem services or project based carbon accounting.

\section{Discussion}

A number of methodological issues complicate the inclusion of above-ground carbon removals in PCFs from managed systems containing trees or shrubs. Nevertheless, it is desirable to include biogenic carbon in their above-ground biomass in PCFs in order to incentivize the efficient use of this renewable resource and improve the assessment of the climate impact of products derived from such systems. There is no absolute right or wrong but it is important to allow fair comparisons between systems and products and 
to enable the aims of PCFs to be met.

Suggestions are made here for considering above-ground carbon removals in perennial systems, including the main crop and co-products, to encourage the planting and maintenance of woody biomass and the use of this biomass either as a source of energy or for long-lived products. The inclusion of increases and decreases in carbon stocks related to management changes recommended here is not required by BSI (2011) and WRI and WBCSD (2011), possibly because they often do not affect the product to be analyzed but other elements of the system, e.g. shade trees.

The approach proposed here encourages individual stakeholders to maintain or increase above-ground carbon stocks which is expected to encourage mitigation efforts at the local scale and under the control of individual farmers, and to disincentivise decreases in carbon stocks.

IPCC (2006) provides methods and default values to calculate changes in carbon stocks as a result of LUC or management changes but improved methods for estimating carbon sequestration in agroforestry systems are needed (Nair and Nair, 2014).

Where benefits can be credited to a system, it is suggested to show emissions and credits separately when presenting PCF results. This allows stakeholders to clearly identify whether sinks were enhanced, fossil energy replaced or GHG emissions reduced in order to achieve a lower PCF, hence enhancing transparency and encouraging efforts to improve on both sources and sinks.

\section{Potential trade-offs}

It is important to consider other environmental aspects in addition to GHG emissions. The efficient use of all products from the same land should be encouraged but removing biomass for energy or other purposes needs to remain at sustainable levels. For example, if the biomass that is usually left behind in smallholder rubber plantations was 
removed there might be unintended consequences for nutrient cycling within the plantation (Ratnasingam et al., 2012).

A consideration of increasing soil carbon levels via biomass left in the plantation was outside the scope of this paper; but clearly this part of the carbon cycle is linked with the rate of extraction of above-ground biomass. This leads to a potential trade-off between climate mitigation via the extraction of biomass (e.g. for bioenergy) or via enhanced levels of soil carbon that should be carefully managed. The latter is a significant climate mitigation option (Paustian et al., 2016), and soil organic matter levels also have important benefits for soil fertility and climate adaptation (Lipper et al., 2014). Similarly, it might be desirable to increase on-farm carbon stocks in shade trees for climate adaptation with may result in a trade-off with both main product yields and the maximization of wood extraction rates.

These potential trade-offs make the inclusion of above-ground carbon sequestration in PCFs complex beyond questions about time scales or co-product allocation. Great care needs to be taken to prevent wrong incentives by encouraging excessive biomass removals. This may require the setting of regional threshold values for biomass extraction encouraged by PCFs. As stocks cannot always be meaningfully included in PCFs, using different methods for incentivizing the maintenance of carbon stocks and reducing PCFs can highlight potential trade-offs while recognizing the importance of both. Finally, PCFs only consider a single environmental problem. Therefore, a good performance in terms of GHG emissions should not be taken to imply overall sustainability or a high ecological value of a system; in order to assess these, a more holistic analysis considering possible trade-offs is required. 


\section{References}

Andrade HJ, Segura MA, Canal DS, Feria M, Alvarado JJ, Marín LM, Pachón D, Gómez MJ (2014) The carbon footprint of coffee production chains in Tolima, Colombia. In: Oelbermann M (ed) Sustainable agroecosystems in climate change mitigation. Wageningen Academic Publishers, Wageningen, The Netherlands.

Bessou C, Basset-Mens C, Tran T, Benoist A (2013) LCA applied to perennial cropping systems: a review focused on the farm stage. International Journal of Life Cycle Assessment 18, 340-361.

BSI (2011) PAS 2050:2011. Specification for the assessment of the life cycle greenhouse gas emissions of goods and services. British Standards, London, UK.

Cederberg C, Persson UM, Neovius K, Molander S, Clift R (2011) Including carbon emissions from deforestation in the carbon footprint of Brazilian beef. Environmental Science and Technology 45, 1773-1779.

Coltro L, Mourad AL, Kletecke RM, Mendonça TA, Germer SPM (2009) Assessing the environmental profile of orange production in Brazil. International Journal of Life Cycle Assessment 14, 656-664.

Dornburg V, Marland G (2008) Temporary storage of carbon in the biosphere does have value for climate change mitigation: a response to the paper by Miko Kirschbaum. Mitigation and Adaptation Strategies for Global Change 13, 211-217.

EC-JRC (2010) European Commission - Joint Research Centre - Institute for Environment and Sustainability International Reference Life Cycle Data System (ILCD) Handbook - General guide for Life Cycle Assessment - Detailed guidance. Publications Office of the European Union, Luxembourg.

Haggar J, Schepp K (2012) Coffee and climate change Impacts and options for adaptation in Brazil, Guatemala, Tanzania and Vietnam. NRI Working Paper Series: Climate change, agriculture and natural resources. Natural Resources Institute, University of Greenwich.

IPCC (2006) 2006 IPCC Guidelines for National Greenhouse Gas Inventories. Prepared by the National Greenhouse Gas Inventories Programme, Eggleston HS, Buendia L, Miwa K, Ngara T, Tanabe K (Eds.), IGES, Japan.

ISO (2013) ISO/TS 14067:2013 Carbon footprint of products-requirements and guidelines for quantification and communication. Geneva, Switzerland.

Jørgensen SV, Hauschild MZ (2013) Need for relevant timescales when crediting temporary carbon storage. International Journal of Life Cycle Assessment 18, 747-754.

Lam MK, Lee KT, Mohamed AR (2009) Life cycle assessment for the production of biodiesel: a case study in Malaysia for palm oil versus jatropha oil. Biofuels, Bioproduction and Biorefining 3, 601-612. 
Lipper L, Thornton P, Campbell BM, Baedeker T, Braimoh A, Bwalya M, Caron P, Cattaneo A, Garrity D, Henry K, Hottle R, Jackson L, Jarvis A, Kossam F, Mann W, McCarthy N, Meybeck A, Neufeldt H, Remington T, Thi Sen P, Sessa R, Shula R, Tibu A, Torquebiau E (2014) Climate smart agriculture for food security. Nature Climate Change 4, 1068-1072.

Maina JJ, Mutwiwa UN, Kituu GM, Githiru M (2016) Evaluation of greenhouse gas emissions along the small-holder coffee supply chain in Kenya. Journal of Sustainable Research in Engineering 2, 111-120.

Mourad AL, Coltro L, Oliveira PAPLV, Kletecke RM, Baddini JPOA (2007) A simple methodology for elaborating the live cycle inventory of agricultural products. International Journal of Life Cycle Assessment 12, 408-413.

Nair PKR, Kumar BM, Nair VD (2009) Agroforestry as a strategy for carbon sequestration. Journal of Plant Nutrition and Soil Science 172, 10-23.

Nair PKR, Nair VD (2014) 'Solid-fluid-gas': the state of knowledge on carbon sequestration potential of agroforestry systems in Africa. Current Opinion in Environmental Sustainability 6, 22-27.

Noponen MRA, Haggar J, Edwards-Jones G, Healey J (2013) Intensification of coffee systems can increase the effectiveness of REDD mechanisms. Agricultural Systems 119, $1-9$.

Paustian K, Lehmann J, Ogle S, Reay D, Robertson GP, Smith P (2016) Climate-smart soils. Nature 532, 49-57.

Plassmann K (2012) Accounting for carbon removals. Nature Climate Change 2, 4-6.

Petsri S, Chidthaisong A, Pumijumnong N, Wachrinrat C (2013) Greenhouse gas emissions and carbon stock change in rubber tree plantations in Thailand from 1990 to 2004. Journal of Cleaner Production 52, 61-70.

Ratnasingam J, Ramasamy G, Ioras F, Kaner J, Wenming L (2012) Production potential of rubberwood in Malaysia: its economic challenges. Notulae Botanicae Horti Agrobotanici 40, 317-322.

Smith P, Bustamante M, Ahammad H, Clark H, Dong H, Elsiddig EA, Haberl H, Harper R, House J, Jafari M, Masera O, Mbow C, Ravindranath NH, Rice CW, Robledo Abad C, Romanovskaya A, Sperling F, Tubiello F (2014) Agriculture, Forestry and Other Land Use (AFOLU). In: Climate Change 2014: Mitigation of Climate Change. Contribution of Working Group III to the Fifth Assessment Report of the Intergovernmental Panel on Climate Change [Edenhofer O, Pichs-Madruga R, Sokona Y, Farahani E, Kadner S, Seyboth K, Adler A, Baum I, Brunner S, Eickemeier P, Kriemann B, Savolainen J, Schlömer S, von Stechow C, Zwickel T, Minx JC (eds.)]. Cambridge University Press, Cambridge, United Kingdom and New York, NY, USA. 
Tscharntke T, Clough Y, Bhagwat SA, Buchori D, Faust H, Hertel D, Hölscher D, Juhrbandt J, Kessler M, Perfecto I, Scherber C, Schroth G, Veldkamp E, Wanger TC (2011) Multifunctional shade-tree management in tropical agroforestry landscapes - a review. Journal of Applied Ecology 48, 619-629.

Vogtländer J, van der Welden NM, van der Lugt P (2014) Carbon sequestration in LCA, a proposal for a new approach based on the global carbon cycle; cases on wood and on bamboo. International Journal of Life Cycle Assessment 19, 13-23.

WRI, WBCSD (2011) Greenhouse Gas Protocol product life cycle accounting and reporting standard. World Resources Institute and World Business Council for Sustainable Development. 